\title{
BACTERIAS HALÓFILAS MODERADAS PRODUCTORAS DE HIDROLASAS DE INTERÉS BIOTECNOLÓGICO
}

\author{
Moderately halophilic bacterias producing hydrolytic biotechnological enzymes
}

\author{
Mónica L. Flores, Amparo I. Zavaleta, Yanina Zambrano, Liliam Cervantes, Víctor Izaguirre \\ Laboratorio de Biología Molecular, Facultad de Farmacia y Bioquímica, Universidad Nacional Mayor de San Marcos
}

\section{RESUMEN}

El objetivo de este estudio fue caracterizar bacterias halófilas moderadas productoras de hidrolasas de interés biotecnológico. Para ello, se seleccionaron 32 aislados bacterianos aerobios procedentes de ambientes salinos de Pilluana, Huacho, Maras, Chilca, Paracas y Ventanilla. Para todos los microorganismos se determinaron: características morfológicas, fisiológicas y capacidad hidrolítica a diversos sustratos. La caracterización genotípica se realizó amplificando los genes ribosómicos bacterianos $16 \mathrm{~S}$ y cortando con la enzima Hae III. Los microorganismos presentaron actividad hidrolítica sobre tween 8o, aceite de oliva, almidón, caseína, lactosa y ADN; correspondiendo cada una de estas moléculas a los números de aislado 23 , 2, 24, 19, 2 y 6, respectivamente. Los aislados $\mathrm{L}_{3} \mathrm{CH}$ y L2PAR hidrolizaron la mayoría de sustratos a excepción de lactosa y ADN, respectivamente. Por otro lado, los aislados P2RI-17 y M17 hidrolizan solamente Tween 8o. Del análisis de restricción del ADN ribosómico $16 \mathrm{~S}$ amplificado se obtuvieron 12 perfiles genéticos, lo cual indica que al menos existen 12 especies bacterianas con gran potencial biotecnológico en la producción de enzimas hidrolíticas.

Palabras clave: Halófilas moderadas, ambientes salinos peruanos, enzimas hidrolítica, ARDRA

\section{SUMMARY}

The aim of this study was to characterize moderately halophilic bacteria producing hydrolases of biotechnological interest. For that, 32 aerobic bacterial isolates were selected from salt environments such as Pilluana, Huacho, Maras, Chilca, Paracas and Ventanilla. The morphological and physiological properties and hydrolytic capacity to various substrates were determined for all isolates. Genotypic characterization was performed by amplification of bacterial 16S ribosomal gene and cutting with the Hae III enzyme. The isolates 23, 2, 24, 19, 2 and 6 showed hydrolytic activity for Tween 8o, olive oil, starch, casein, lactose and DNA, respectively. Isolates $\mathrm{L}_{3} \mathrm{CH}$ and $\mathrm{L}_{2} \mathrm{PAR}$ hydrolyzed the most substrates, except for lactose and DNA, in contrast isolates P2RI-7 and Mi7 which only hydrolyze Tween 8o. Twelve genetic profiles were obtained from the restriction analysis of amplified 16S ribosomal DNA restriction analysis, indicating that there are at least 12 bacterial species with high biotechnological potential for hydrolytic enzyme production.

Key words: Moderate halophiles, peruvian salt environments, hydrolytic enzymes, ARDRA

\section{INTRODUCCIÓN}

os microorganismos halófilos han desarrollado complejos procesos de adaptación que les han permitido hacer frente a las condiciones ambientales extremas que caracterizan a los ambientes salinos. Uno de los más importantes mecanismos de adaptación que han desarrollado estos microorganismos es la acumulación intracelular de solutos u osmolitos compatibles, y cuya principal característica es la de no interactuar con el metabolismo celular, por lo que su función es puramente osmótica ${ }^{(1,2)}$.

Las bacterias halófilas moderadas crecen óptimamente en un rango de salinidad de o,5 a 2,5 M; además producen una serie de enzimas hidrolíticas extracelulares tales como: amilasas, proteasas, lipasas, nucleasas y esterasas ${ }^{(3,4)}$.
En los últimos años, el interés por el estudio de estas enzimas se ha incrementado debido a sus propiedades catalíticas y potencial aplicación industrial en la formulación de detergentes, elaboración de productos dietéticos, procesamiento de cuero, papel y alimentos cárnicos; así como también en la síntesis de enantiómeros puros de fármacos, biodegradación de residuos tóxicos y contaminantes industriales, entre otros ${ }^{(4,5)}$.

Actualmente, las industrias requieren procesos tecnológicos eficientes y limpios, es por ello que el uso de microorganismos aislados de ambientes extremos, o sus enzimas, constituye una excelente opción para satisfacer esta creciente demanda del mercado biotecnológico. Por ello, el presente estudio tuvo como finalidad aislar y seleccionar bacterias con capacidad de producir enzimas extracelulares de interés o aplicación biotecnológica procedentes de diversos ambientes salinos del 
Perú.

\section{MATERIALES Y MÉTODOS}

Cultivo de bacterias. Los 32 aislados bacterianos que se utilizaron en este estudio pertenecen al cepario de bacterias halófilas del Laboratorio de Biología Molecular de la Facultad de Farmacia y Bioquímica de la Universidad Nacional Mayor de San Marcos (Lima - Perú), los cuales provienen de diferentes ambientes salinos de Pilluana, Huacho, Maras, Chilca, Paracas y Ventanilla. Los aislados seleccionados crecieron óptimamente en medio agua de sales (SW, Sea Water) al 10\% conteniendo extracto de levadura al o,5\%. Para las pruebas fisiológicas e hidrolíticas se utilizó la metodología descrita por Sánchez-Porro y col. y por Ventosa y col. ${ }^{(5,6)}$.

Características morfológicas. El tamaño, color y consistencia de las colonias se determinó a partir de cultivos de $24 \mathrm{~h}$ en medio SW sólido. Para la determinación del tipo de pared celular y forma bacteriana se utilizaron cultivos frescos de $14 \mathrm{~h}^{(7)}$.

Pruebas fisiológicas. Los aislados se inocularon en medio SW líquido enriquecido con extracto de levadura al o, $5 \%$, conteniendo además agua de sales a concentraciones de o, 5, 10, 15, 20 y $25 \%$. Luego los cultivos bacterianos se incubaron a $37^{\circ} \mathrm{C}$ por 24 $\mathrm{h}$, la densidad celular se determinó por espectrofotometría a 600 ๆm. Para determinar el pH óptimo de crecimiento se utilizó caldo $\mathrm{SW}$ al 10\%, cuyo $\mathrm{pH}$ fue ajustado a 6,5; 7,5 y 8,5 con $\mathrm{NaOH} 1 \mathrm{~N}$ y $\mathrm{HCl}_{1}$ N. Los medios luego fueron incubados a $37^{\circ} \mathrm{C}$ por 24 horas. La temperatura óptima se determinó empleando el medio SW líquido al 10\%, los aislados se cultivaron a: 20,37 y $45^{\circ} \mathrm{C}$.

\section{Actividad hidrolítica a diversos sustratos}

Almidón. La actividad amilolítica se detectó según el método descrito por Cowan y Steel en 1993. Para este ensayo se utilizó el agar almidón (DIFCO) al $10 \%$ de $\mathrm{SW}$, el pH se ajustó a 7,2. Las placas se incubaron durante dos días a $37^{\circ} \mathrm{C}$. La posterior lectura se realizó añadiendo $10 \mathrm{~mL}$ de lugol sobre las placas. Se consideró reacción positiva cuando se observó la formación de halos claros alrededor de las colonias productoras de amilasas ${ }^{(8,9)}$.

Lípidos. La actividad lipolítica se determinó por su capacidad de hidrolizar tween 80 y aceite de oliva. Los aislados se sembraron en medio sólido SW al 10\% conteniendo los sustratos lipídicos al $1 \%$. Las placas se incubaron a $37^{\circ} \mathrm{C}$ hasta por tres días. La lectura fue directa, así la hidrólisis de es- tos sustratos se evaluó según lo descrito por SánchezPorro y col. ${ }^{(5)}$.

Caseína. La capacidad para hidrolizar caseína se determinó según el método descrito por Collins en 1989. El medio utilizado fue agar caseína, al que se le agregó solución stock de sales, hasta obtener $10 \%$ de sales como concentración final del medio. El período de incubación, para los aislados, fue de tres días a $37^{\circ} \mathrm{C}$. La reacción se consideró positiva cuando alrededor de las colonias se formó un halo claro de proteólisis ${ }^{(10)}$.

Ácidos nucleicos. Para determinar la capacidad de hidrolizar ácidos nucleicos se utilizó agar SW al 10\% suplementado con ADN al 1\%. Luego las placas se incubaron a $37^{\circ} \mathrm{C}$ hasta por 3 días. La lectura fue directa, así la hidrólisis de estos sustratos se evaluó según lo descrito por Sánchez-Porro y col. ${ }^{(5)}$.

Lactosa. Se centrifugaron $0,2 \mathrm{~mL}$ del cultivo bacteriano de 18 h, las células se resuspendieron en o,2 mL de

Tabla 1. Características morfológicas de las bacterias halófilas moderadas

\begin{tabular}{|c|c|c|c|c|c|c|}
\hline Aislado & Procedencia & Color & Consistencia & Tamaño & $\begin{array}{c}\text { Tinción } \\
\text { Gram }\end{array}$ & Forma \\
\hline PDII-1 & Pilluana & crema & gomosa & grande & - & bacilo \\
\hline PDI-4 & Pilluana & crema & gomosa & grande & - & bacilo \\
\hline PDI-5 & Pilluana & crema & gomosa & grande & - & bacilo \\
\hline P3CII-1 & Pilluana & crema & gomosa & grande & - & coco \\
\hline P2CII-3 & Pilluana & crema & gomosa & grande & + & bacilo \\
\hline P2CII-1 & Pilluana & crema & gomosa & grande & - & bacilo \\
\hline P2RI-7 & Pilluana & rojo & gomosa & grande & - & coco \\
\hline P2CI-5 & Pilluana & crema & gomosa & grande & - & bacilo \\
\hline $\mathrm{H}-17$ & Huacho & crema & gomosa & grande & + & bacilo \\
\hline $\mathrm{H}-19$ & Huacho & melón & gomosa & grande & - & bacilo \\
\hline $\mathrm{H}-22$ & Huacho & melón & gomosa & grande & - & bacilo \\
\hline $\mathrm{H}-23$ & Huacho & crema & gomosa & grande & - & bacilo \\
\hline $\mathrm{H}-26$ & Huacho & melón & gomosa & grande & - & bacilo \\
\hline M20 & Maras & crema & lisa & pequeña & - & bacilo \\
\hline M19 & Maras & crema & gomosa & grande & - & bacilo \\
\hline M17 & Maras & crema & gomosa & grande & - & bacilo \\
\hline M12 & Maras & crema & gomosa & grande & - & bacilo \\
\hline M11 & Maras & crema & gomosa & grande & - & bacilo \\
\hline M08 & Maras & crema & gomosa & grande & - & bacilo \\
\hline M07 & Maras & crema & lisa & pequeña & - & bacilo \\
\hline $\mathrm{L} 2 \mathrm{CH}$ & Chilca & crema & gomosa & grande & - & bacilo \\
\hline $\mathrm{L} 3 \mathrm{CH}$ & Chilca & crema & gomosa & grande & - & bacilo \\
\hline L1PAR & Paracas & crema & gomosa & grande & - & bacilo \\
\hline L2PAR & Paracas & blanca & gomosa & grande & - & bacilo \\
\hline LAP & Pilluana & crema & gomosa & grande & - & bacilo \\
\hline LBP & Pilluana & blanca & gomosa & grande & - & bacilo \\
\hline LC1P & Pilluana & blanca & lisa & pequeña & - & bacilo \\
\hline LKRP & Pilluana & naranja & lisa & pequeña & - & bacilo \\
\hline VI-2 & Ventanilla & crema & gomosa & grande & - & coco \\
\hline VII-4 & Ventanilla & naranja & lisa & pequeña & - & bacilo \\
\hline VIII-6 & Ventanilla & naranja & lisa & pequeña & - & coco \\
\hline VI-1 & Ventanilla & crema & gomosa & grande & - & bacilo \\
\hline
\end{tabular}


Tabla 2. Características fisiológicas de las bacterias halófilas moderadas

\begin{tabular}{|c|c|c|c|c|c|c|c|c|c|c|c|c|}
\hline \multirow{3}{*}{ Aislado } & \multicolumn{12}{|c|}{ Características fisiológicas } \\
\hline & \multicolumn{6}{|c|}{ Concentración de sales (\%) } & \multicolumn{3}{|c|}{$\mathrm{pH}$} & \multicolumn{3}{|c|}{ Temperatura $\left({ }^{\circ} \mathrm{C}\right)$} \\
\hline & 0 & 5 & 10 & 15 & 20 & 25 & 6,5 & 7,5 & 8,5 & 20 & 37 & 42 \\
\hline PDII-1 & - & +++ & ++ & ++ & ++ & + & + & +++ & ++ & + & +++ & +++ \\
\hline PDI-4 & - & +++ & +++ & ++ & + & + & ++ & +++ & + & + & +++ & +++ \\
\hline PDI-5 & - & +++ & +++ & ++ & ++ & + & + & +++ & + & + & +++ & +++ \\
\hline P3CII-1 & - & +++ & +++ & +++ & +++ & ++ & + & +++ & + & + & +++ & +++ \\
\hline P2CII-3 & - & +++ & +++ & +++ & ++ & ++ & ++ & +++ & ++ & + & +++ & +++ \\
\hline P2CII-1 & - & ++ & +++ & +++ & +++ & + & + & +++ & + & + & +++ & +++ \\
\hline P2RI-7 & - & ++ & +++ & ++ & ++ & ++ & +++ & +++ & ++ & + & +++ & +++ \\
\hline P2CI-5 & - & ++ & +++ & ++ & ++ & ++ & + & +++ & + & + & +++ & ++ \\
\hline $\mathrm{H}-17$ & - & ++ & +++ & +++ & + & + & + & +++ & + & + & +++ & ++ \\
\hline H-19 & - & + & +++ & +++ & + & + & + & +++ & + & + & +++ & ++ \\
\hline $\mathrm{H}-22$ & - & ++ & +++ & ++ & + & + & ++ & +++ & + & + & +++ & ++ \\
\hline $\mathrm{H}-23$ & - & + & +++ & +++ & ++ & + & ++ & +++ & + & ++ & +++ & ++ \\
\hline $\mathrm{H}-26$ & - & ++ & +++ & + & + & + & ++ & +++ & + & + & +++ & ++ \\
\hline M20 & - & +++ & +++ & +++ & ++ & + & +++ & +++ & +++ & + & +++ & ++ \\
\hline M19 & - & +++ & +++ & +++ & ++ & - & +++ & +++ & ++ & + & +++ & ++ \\
\hline M17 & - & +++ & +++ & +++ & ++ & - & +++ & +++ & ++ & + & +++ & ++ \\
\hline M12 & - & +++ & +++ & +++ & ++ & + & ++ & +++ & + & + & +++ & + \\
\hline M11 & - & +++ & +++ & +++ & ++ & - & +++ & +++ & + & + & +++ & ++ \\
\hline M08 & - & +++ & +++ & +++ & ++ & - & +++ & +++ & + & - & +++ & ++ \\
\hline M07 & - & +++ & +++ & +++ & ++ & + & +++ & +++ & + & - & +++ & ++ \\
\hline LAP & - & ++ & +++ & ++ & ++ & + & + & +++ & + & + & +++ & + \\
\hline LBP & - & ++ & +++ & ++ & + & - & + & +++ & + & + & +++ & + \\
\hline LC1P & - & ++ & +++ & ++ & + & - & - & +++ & + & + & +++ & + \\
\hline LKRP & - & ++ & ++ & +++ & ++ & + & + & +++ & + & + & +++ & + \\
\hline $\mathrm{L} 1 \mathrm{CH}$ & - & ++ & +++ & ++ & + & - & ++ & +++ & + & - & +++ & + \\
\hline $\mathrm{L} 2 \mathrm{CH}$ & - & + & +++ & ++ & + & - & + & +++ & + & + & +++ & + \\
\hline L2PAR & - & ++ & +++ & +++ & ++ & + & + & +++ & + & + & +++ & - \\
\hline L3PAR & - & ++ & +++ & ++ & ++ & + & + & +++ & + & ++ & +++ & - \\
\hline VI-2 & - & +++ & +++ & + & - & - & + & +++ & + & + & +++ & ++ \\
\hline VII-4 & - & +++ & +++ & + & - & - & + & +++ & ++ & + & +++ & - \\
\hline VIII-6 & - & +++ & +++ & + & - & - & + & +++ & + & + & +++ & ++ \\
\hline VI-1 & - & +++ & +++ & + & - & - & + & +++ & ++ & + & +++ & + \\
\hline
\end{tabular}

Densidad óptica medida por espectrofotometría a $600 \mathrm{~nm}:<0.1,-; \geq 0.1,+; \geq 0.4,++; \geq 0.8,+++$

buffer fosfato salino conteniendo orto-nitrofenil-galactopiranósido y se incubaron a $37^{\circ} \mathrm{C}$ durante cuatro h, la coloración amarilla tenue e intensa indicó reacción parcial y total respectivamente.

Análisis de restricción del ADN ribosómico amplificado. Se obtuvo ADN genómico de cultivos bacterianos de $12 \mathrm{~h}$ utilizando el método físico de lisis por temperatura a $85^{\circ} \mathrm{C}{ }^{(11)}$. Los genes ribosómicos $16 \mathrm{~S}$ se amplificaron por la reacción en cadena de la polimerasa utilizando cebadores universales específicos para bacterias ${ }^{(13)}$. Los productos amplificados fueron cortados con la enzima Hae III, siguiendo las especificaciones de los fabricantes. El ADN cortado se separó por electroforesis en geles de agarosa "NueSieve" ${ }^{\circledR}$ al 3\% usando buffer TBE o,5X y el marcador de peso molecular $\Phi$ X/Hae III. Los perfiles de restricción se visualizaron por luz UV, previa coloración con bromuro de etidio.

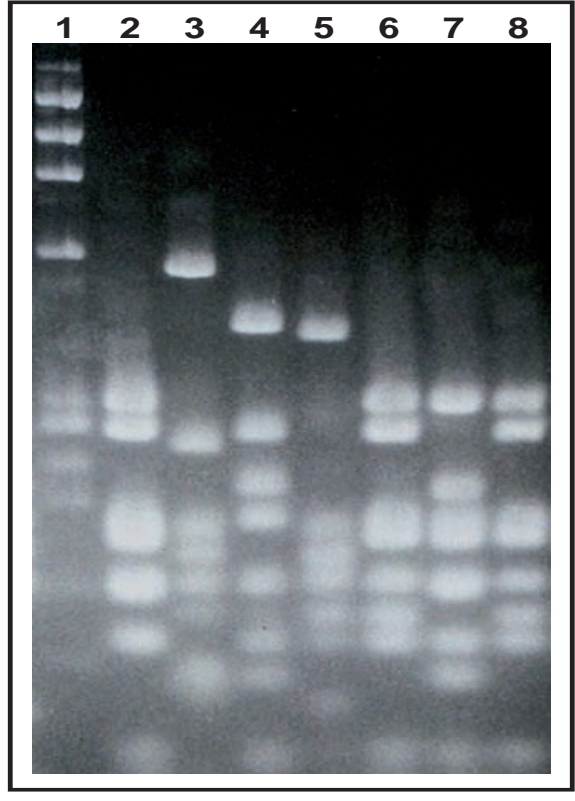

Figura 1. Gel de agarosa mostrando los genes ribosómicos $16 \mathrm{~S}$ amplificados y cortados con Hae III. Línea (número): 1, Ladder $1 \mathrm{~kb}$ + ФX/HaeIII; 2 - 6, aislados de las salinas de Pilluana; 7 y 8 , aislados de Chilca.

\section{RESULTADOS}

Las bacterias estudiadas fueron aisladas previamente de aguas saladas provenientes de las tres regiones geográficas del Perú en las siguientes proporciones: selva (Salinas de Pilluana - San Martín) 37,50\% (12/32), sierra (Salinas de Maras - Cusco) 21,88\% (7/32) y costa (Salinas de Chilca y Huacho - Lima, Bahía de Paracas - Ica, Mar de Ventanilla - Callao) 40,62\% (13/32). Los aislados formaron colonias de coloración naranja, crema, blanca, melón y rojo, prevaleciendo las cremas con el $69 \%(22 / 32)$ y las de consistencia gomosa el 81\% (26/32). Mediante tinción Gram y microscopía óptica se determinó que el 87,5 y 12,5\% de los aislados fueron bacilos y cocos respectivamente, el 94\% (30/32) son bacterias Gram negativas (tabla 1).

Los aislados bacterianos estudiados crecen en medio SW entre 5 y $15 \%$ de sales; el 84 (27/32) y 59\% (19/32) crecen hasta con 20 y $25 \%$ de sales, respectivamente; en estas últimas concentraciones los aislados presentan dificultad de crecimiento, evidenciado por las bajas densidades celulares obtenidas. Cabe resaltar que las bacterias VI-2, VII-4, VIII-6, VI-1 aisladas del Mar de Ventanilla crecen rápidamente a 5 y $10 \%$ de sales; sin embargo, a medida que se incrementa la concentración 
salina, el crecimiento disminuye hasta que se inhibe a partir del $20 \%$ de sales (tabla 2). Todos los aislados crecen óptimamente a $37{ }^{\circ} \mathrm{C} \mathrm{y} \mathrm{pH} \mathrm{7,5,} \mathrm{el} \mathrm{22 \%} \mathrm{(7/32)} \mathrm{a} \mathrm{pH}$ 6,5 y un aislado a $\mathrm{pH} 8,5$; a la vez, el $91 \%(29 / 32)$ de las bacterias crecen a $42{ }^{\circ} \mathrm{C}$. El $22 \%(7 / 32)$ de los aislados que crecen a $42{ }^{\circ} \mathrm{C}$, provienen de las salinas tropicales de Pilluana en San Martín (tabla 2).

Con respecto a la capacidad hidrolítica de las bacterias halófilas moderadas, éstas degradan de uno a cinco sustratos, sin considerar la hidrólisis parcial de la lactosa. En la tabla 3, se puede observar que 2, 12, 14, 2 y 2 aislados degradan 1, 2, 3, 4 y 5 sustratos respectivamente; el 81\% hidrolizan de 2 a 3 sustratos. Los aislados VI-1 y VI-2 degradan 4 sustratos y $\mathrm{L}_{3} \mathrm{CH}$ y L2PAR hidrolizan 5 cada uno; en ambos casos, las bacterias proceden de ambientes marinos de la costa peruana tales como Ventanilla, Chilca y Paracas. El tween 8o, el almidón y la caseína son utilizados por el 72, 75 y $59 \%$ de las bacterias estudiadas respectivamente; el aceite de oliva y la lactosa son utilizados por dos microorganismos en cada caso (tabla 3).

En la figura 1 se presenta un gel de agarosa con 6 perfiles de ADN ribosómico $16 \mathrm{~S}$ distintos correspondientes a aislados procedentes de las salinas de Pilluana. Dado que los genes ribosómicos 16S son muy conservados, esta variación en los perfiles génicos indicaría la presencia de especies diferentes.

\section{DISCUSIÓN}

Los ambientes salinos generalmente contienen concentraciones de sales iguales o superiores al agua marina, donde habitan una gran diversidad de microorganismos adaptados a condiciones restrictivas de temperatura, $\mathrm{pH}$, salinidad y contenido iónico ${ }^{(5,13)}$. Todos los microorganismos en estudio demostraron ser capaces de crecer en un rango de salinidad de 5 a $25 \%$; además de presentar en su mayoría una concentración salina optima de 10\%; en base a ello y desde un punto de vista fisiológico se puede inferir válidamente que todos los aislados son halófilos moderados ${ }^{(2,13)}$.

El predominio de las bacterias Gram negativas en ambientes salinos es común, la mayoría de especies halófilas descritas son bacilos ${ }^{(6,14)}$. Así, el 87,5\% de bacterias estudiadas de ambientes salinos peruanos son bacilos Gram negativos (tabla 1). En salares de zonas geográficas diversas se han descrito bacterias halófilas moderadas de forma bacilar con predominancia de los géneros Halomonas, Chromohalobacter, Salinobacter, Marinobacter, Idiomarina, etc ${ }^{(13,14)}$.

La mayoría de bacterias degradan tween 8o, al-
Tabla 3. Perfiles hidrolíticos de las bacterias halófilas moderadas

\begin{tabular}{|c|c|c|c|c|c|c|}
\hline \multirow[b]{2}{*}{ Aislado } & \multicolumn{6}{|c|}{ Actividad hidrolítica } \\
\hline & $\begin{array}{c}\text { Tween } \\
\mathbf{8 0}\end{array}$ & $\begin{array}{c}\text { Aceite de } \\
\text { oliva }\end{array}$ & Almidón & Caseína & Lactosa & ADN \\
\hline PDII-1 & +++ & - & + & +++ & \pm & - \\
\hline PDI-4 & +++ & - & + & - & - & ++ \\
\hline PDI-5 & + & - & + & + & \pm & - \\
\hline P3CII-1 & - & - & + & +++ & \pm & - \\
\hline P2CII-3 & - & - & + & - & \pm & ++ \\
\hline P2CII-1 & ++ & - & + & - & - & - \\
\hline P2RI-7 & ++ & - & - & - & - & - \\
\hline P2CI-5 & +++ & - & + & - & \pm & - \\
\hline $\mathrm{H}-17$ & + & - & - & ++ & - & - \\
\hline $\mathrm{H}-19$ & + & - & - & ++ & \pm & - \\
\hline $\mathrm{H}-22$ & ++ & - & + & - & - & - \\
\hline $\mathrm{H}-23$ & - & - & +++ & - & \pm & - \\
\hline H-26 & ++ & - & + & + & \pm & - \\
\hline M20 & - & - & + & +++ & - & - \\
\hline M19 & - & - & ++ & - & - & - \\
\hline M17 & + & - & - & - & - & - \\
\hline M12 & - & - & - & +++ & \pm & - \\
\hline M11 & - & - & - & - & - & + \\
\hline M08 & - & - & + & - & \pm & - \\
\hline M07 & - & - & + & + & \pm & - \\
\hline $\mathrm{L} 2 \mathrm{CH}$ & ++ & - & +++ & ++ & - & - \\
\hline $\mathrm{L} 3 \mathrm{CH}$ & + & +++ & + & +++ & - & ++ \\
\hline L1PAR & +++ & - & +++ & + & \pm & - \\
\hline L2PAR & +++ & +++ & +++ & + & + & - \\
\hline LAP & +++ & - & +++ & + & - & - \\
\hline LBP & +++ & - & + & +++ & \pm & - \\
\hline LC1P & + & - & + & +++ & \pm & - \\
\hline LKRP & + & - & - & - & + & - \\
\hline VI-2 & + & - & ++ & +++ & - & ++ \\
\hline VII-4 & +++ & - & ++ & - & \pm & - \\
\hline VIII-6 & + & - & - & +++ & \pm & - \\
\hline VI-1 & ++ & - & + & + & - & ++ \\
\hline
\end{tabular}

Tamaño de halo de hidrólisis $(\mathrm{mm}):-, 0 ;+, \leq 5 ;++,>6 ;+++,>15$.

Hidrólisis de la lactosa en medio líquido: -, ninguna; \pm , parcial; +, total

midón y caseína como fuentes de carbono y nitrógeno, pero en diferentes grados valorados en el tamaño del halo de hidrólisis (tabla 3). La capacidad de hidrólisis y la frecuencia de uso de un sustrato u otro dependen de la cepa y del lugar de procedencia. Así por ejemplo, sólo dos bacterias degradan aceite de oliva y otras dos lactosa, de estos resultados se puede inferir que la mayoría de microorganismos estudiados no estuvieron expuestos a estos sustratos. Al respecto, Margesin ${ }^{(3)} \mathrm{y}$ Galinski ${ }^{(15)}$ han descrito que los perfiles hidrolíticos de las bacterias halófilas son muy variados y disímiles entre sí; es por ello que por su gran variedad de perfiles catalíticos, estos microorganismos presentan gran potencial en procesos industriales.

En las 32 bacterias halófilas moderadas procedentes de seis ambientes salinos del Perú existen al menos 
doce especies según el análisis de los perfiles de restricción de los genes ribosómicos $16 \mathrm{~S}$ amplificados y cortados con Hae III. La mayoría de aislados estudiados son bacilos Gram negativos de consistencia gomosa y color crema que crecen óptimamente entre 5 a $10 \%$ de sales, a $\mathrm{pH} 7,5$ y $37^{\circ} \mathrm{C}$. Las bacterias analizadas por su variado perfil hidrolítico constituyen fuentes nativas potenciales en la degradación y la síntesis de nuevos compuestos en un contexto ambiental limpio y sostenible.

\section{AGRADECIMIENTOS}

Este estudio fue financiado parcialmente por los contratos № 162/2006 CONCYTEC/OAJ, VRI/070403021/o80403011, 017/FINCYT/PIBAP/2008.

\section{REFERENCIAS BIBLIOGRÁFICAS}

1. Rodriguez-Valera F, Ruiz-Berraquero F, RamosCormenzana A. Characteristic of the heterotropic bacterial population in hypersaline enviroments of different salt concentrations. Microb Ecol 1981; 7(3): 235-43.

2. Ventosa A, Nieto JJ, Oren A. Biology of moderately halophilic aerobic bacteria. Microbiol Mol Biol Rev 1998; 62(2): 504-44.

3. Margesin R, Schinner F. Potential of halotolerant and halophilic microorganisms for biotechnology. Extremophiles 2001; 5(2): 73-83.

4. Ventosa A, Sanchez-Porro C, Martin S, Mellado E. Halophilic archea and bacteria as source of extracellular hydrolytic enzymes. In N: Gunde-Cimerman, A. Oren y A Plemenitas (eds). Adaptation to life at salt concentrations in Archaea, Bacteria, and Eukarya. Heildeberg: Spring-Verlag 2005.

5. Sánchez-Porro C, Martín S, Mellado E, Ventosa A. Diversity of moderately halophilic bacteria producing extracellular hydrolytic enzymes. J Appl Microbiol 2003; 94(2): 295-300.

6. Ventosa A, Quesada E, Rodríguez-Valera F, Ruíz Berraquero F, Ramos-Cormenzana A. Numerical taxonomy of moderately halophilic-negative rods. J Gen Microbiol 1982; 128: 1959-68
7. Jenkins D, Richard MG, Daigger GT. Manual on the causes and control of activated sludge bulking and foaming. 2a ed. Lewis Publishers. Nueva York, 1993.

8. Cowan ST, Steel LJ. Manual for the Identification of Medical Bacteria, za ed. Cambridge University Press. UK, 1993.

9. British Pharmacopeia. London: The Pharmaceutical Press 1963.

10. Collins CH, Lyne PM. Métodos microbiológicos. Acribia. Zaragoza, 1989.

11. Clarke L, Millar BC, Moore JE. Extraction of genomic DNA from Pseudomonas aeruginosa: A comparison of three methods. Br J Biomed Sci 2003; 6o(1): 34-35.

12. Mendoza-Espinoza A, Koga Y, Zavaleta AI. Amplified $16 \mathrm{~S}$ ribosomal DNA restriction analysis for identification of Avibacterium paragallinarum. Avian Diseases 2008; 52(1): 54-58.

13. Benlloch S, López-López A, Casamayor EO, Ovreas L, Goddart V, Daae FL, et al. Prokariotic genetic diversity throughout the salinity gradient of a coastal solar saltern. Environ Microbiol 2002; 4(6): 349-6o.

14. Arahal DR, Ludwig W, Schleifer KH, Ventosa A. Phylogeny of the family Halomonadaceae based on ${ }_{23} \mathrm{~S}$ and $16 \mathrm{~S}$ rDNA sequence analyses. Int J Syst Evol Microbiol 2002; 52: 241-49.

15. Galinski EA, Tindall BJ. Biotechnological prospects for halophiles and halotolerant microorganisms. En: Molecular biology and biotechnology of extremophiles. Glasgow: Blackie; 1992. p. 76-114.

Manuscrito recibido el: 05/07/2010

Aceptado para su publicación el: 11/08/2010

\section{Correspondencia:}

Nombre: Amparo Zavaleta Pesantes Dirección: Jr. Puno 1002 - Lima 1 - Perú. e-mail: azavaletap@unmsm.edu.pe 